the NINA accelerator to inject particles at $3 \mathrm{GeV}$ into the machine. The small size of the beam at this energy seems to give some saving in the size of the magnets involved.

The only electron accelerator with an energy reaching $20 \mathrm{GeV}$ is the linear accelerator at Stanford. Such machines produce beams of particles in pulses to allow for cooling of the radio frequency generators and waveguides. The accelerator envisaged by the Daresbury group has the advantage of a longer duty cycle than the Stanford accelerator, however, which would make it a more versatile machine. What chance the Daresbury dosign has of being built is a different matter. At an estimated cost of just over $\mathfrak{E} 3$ million it may be good value for a $20 \mathrm{GeV}$ machine, but the likelihood of the Science Research Council finding this kind of money must be small.

\section{Students and Vice-Chancellors}

ON the surface, at least, the confrontation between British university students and their vice-chancellors is exceedingly decorous. Last week-end most of the executive heads of British universities gathered in Downing College, Cambridge, where they apparently spent a good deal of their time alarming each other with previously unpublicized stories of insurrection or the threat of it. It is not therefore surprising that the vice-chancellors should have issued a statement after their meeting which roundly condemned the wild goings-on of recent weeks. "We utterly condemn, and will resist, attempts by extremist groups to obstruct or disrupt the life of the universities. Such activities destroy freedom of speech and the freedom to learn, and we believe that they are entirely unacceptable to the overwhelming majority of members of the British universities, staff and students alike." The same statement went on to acknowledge the constructive interest of a large part of the student body in the affairs of the universities, promised that there "is scope for them to do more" but insisted that there are "important academic and financial matters" on which the members of universities with "continuing responsibility" must continue to be in charge. The statcment finished with a promise to work out "suitable arrangements" within individual universities and, in particular, to consider the "specific and important points" to which the National Union of Students has drawn attention.

By itself, there is no means of knowing whether this statement will satisfy the somewhat belligerent demands which the National Union of Students made public just over a week ago, although it is also possible that some of the bellicosity which the students have been showing stems from the wish of the students' organizations not to become entirely alienated from their more radical supporters. Briefly, the students are asking for "effective student presence on all relevant college committees", staff-student control of discipline, student control of their own organizations and staffstudent discussion of course content and teaching methods. On examinations, the students are looking for prompt "radical reform", though it is not entirely clear what they mean by this. One tendency is to ask for the abolition of formal examinations, but another asks that there should be some kind of external assessment of the grades which students are awarded. In one sense, however, the National Union of Students appears to have forced its own hand by asking that the programme of reform should be completed before the beginning of the next academic year. Unless somebody does something to make this hope come true, there is at least a chance that, when the new academic year begins, the first signs of trouble will show themselves within the students' organizations.

\section{Gas-cooled Fast Reactor}

Designs for fast breeder reactors seem to be proliferating almost as fast as those for conventional thermal systems. Several months ago the European Nuclear Energy Agency announced that it was investigating the possibility of building a fast reactor cooled either by gas or by steam, in contrast with the liquid sodium cooling which is being used by the UK Atomic Energy Authority, among others. Now Gulf General Atomic in the United States has announced a $\$ 5 \cdot 3$ million joint project which is intended to speed up the development of a gas-cooled system. The project, to be jointly supported by Gulf and twenty-one United States electric power companies, complements another study already in progress and supported jointly by Gulf and the Swiss Federal Institute for Reactor Research at Wurenlingen.

The project just announced by Gulf covers fast reactor core design and development, systems and component development, and safety analysis. Gulf hopes that the system will have a high breeding gain$1 \cdot 5-1 \cdot 6$ - giving low fuel costs, and that the capital cost of the system will be less than that for liquid metal-cooled systems. If all goes well, Gulf vice-president Dr Frederick de Hoffman visualizes the building of a full-scale power station by the early cighties.

\section{Good Food Guide}

ANYBODY worried about the colour of processed peas, the use of silicones by plastic surgeons or the danger of going blind from eating fresh cassava, should seek advice from the British Industrial Biological Research Association. BIBRA is supported jointly by industry, Government and a few charities and assesses the possible hazards to health of materials which member companies develop, manufacture or use. These materials are chiefly used in food technology-food additives and packaging - but also include drugs, cosmetics, toiletries and pesticides; the association hopes eventually to cover all potential environmental hazards.

The association lost its first director, Dr L. Goldberg, to the United States a year ago; he has been replaced by $\operatorname{Dr}$ R. F. Crampton, a biochemist who was the medical director of Abbott Laboratories, Ltd. At the opening of a new $£ 60,000$ extension, Dr Crampton stressed that the association is unique in Great Britain and Europe, and possibly the world, in the way it is organized and financed. For every $\mathfrak{£} 100$ donated by British industry, the Government contributes $£ 150$. In addition, the Nuffield Foundation is contributing $£ 30,000$ a year for six years and the Wellcome Foundation will be sponsoring a study on the neurological effects of cyanide and fresh vitamin $B_{12}$ - found in fresh cassavas and suspected to be the cause of blinciness and paralysis in parts of Nigeria.

In return for these funds, which totalled more than $£ 250,000$ last year, the association acts as a consultancy 
service to its members in Britain and abroad, conduct. ing research on problems presented by the companies. It also provides information on British and foreign legislation relating to food additives, cosmetics, packaging materials and pesticides, and it gives advice on the design, results and adequacy of toxicity tests carried out by the member companies. Because the Government insists on reviewing various groups of food additives every five years, an important part of the association's work each year involves carrying out additional tests on those groups coming up for review.

\section{Committee Power}

A REPORT of professional manpower published by five learned institutions in Britain last week is in the traditional mould. It sets out from the same premises, uses the same figures and predictably enough reaches much the same conclusions as the manpower reports already published. This is not surprising, as the authors of the previous reports, Dr F. S. Dainton, Mr G. S. Bosworth, Professor M. M. Swann and Lord Jackson, were all connected with the committce which has produced the latest report. The Council for Engineering Institutions set up the committee, whose aim it was to produce in abbreviated form the collective wisdom of the previous reports. The argument is that busy academics and businessmen have no time to consult the original sources, but would welcome being told the conclusions in an easily digested form.

As the report points out, the members of the committee served in their own capacities, not as representatives of the organizations which nominated them. The fact that members were nominated by the CEI, the Confederation of British Industry, the Royal Society, the Institute of Physics and the Physical Society (a single learned society, despite its name) and the Royal Institute of Chemistry is therefore not strictly relevant, though it is prominently displayed on the front of the broadsheet. After a few sentences from the Duke of Edinburgh, the report deals briskly with the problems, and goes on to suggest ways in which government departments, industry, professional institutions, universities and schools can help to solve them. The most sensible of the recommendations are those which lend support to the idea of much broader degrees at British universities, though the assumption that this would help to recruit more students to courses in science is not argued. The report accepts that there is "a serious shortage of highly qualified manpower", which is likely to get worse rather than better. To cure it, it suggests that the UGC should discriminate in favour of "disciplines that economic facts dictate are essential to community needs". 'This discrimination must start in the schools and continue in the universities, with grants (or loans, the report adds darkly) used as controls.

The report conveniently ignores reports published outside the British Isles, such as those recently produced by OECD on the technology gap. One of these contains some remarkable figures, which ought to have given the committee pause for thought. All those countries the economic performance of which is rated higher than that of Britain-the United States, France, Germany and Japan-produce fewer technologists as a proportion of the population at risk. The UK, according to OECD, is ahead of all other OECD countries in the production of technologists, and ahead of all but the United States in the production of scientists. One member of the committee had read the report, apparently, but no attempt was made to evaluate it. Perhaps the committee members simply refused to believe it, but if so they should have said so. In any case, there must be serious doubt whether industrialists and academics who have remained deaf to the pleas of the Jackson, Swann, Jones and Dainton reports will be moved by the obiter dicta of the CEI. The most amusing aspects of the report are those in which compromises have been necessary tiu secure the approval of the non-representatives of the CIBI. On the subject of the availability of risk-capital. for example, the committee could hardly give open support to the possibility that the Government might provide it through the Industrial Expansion Bill, because the CBI regards that as a mischievous measure. The report therefore calls on the Government to "foster a climate in which adequate provision can be made for risk finance for research and development projects of potential long-term benefit, and for their commercial exploitation". That could mean almost anything, or: nothing.

\section{More Nutrition Research}

A NEw extension to the Dunn Nutritional Laboratory, set amid the lush green background of Cambridge, was officially opened on June 17 by Sir Rudolph Peters and Dame Harriette Chick. Despite the garden party atmosphere, even a casual look around the superbly equipped new accommodation revealed that serious work is in progress and that every effort is being made to maintain the laboratory's excellent record under the directorship of Dr E. Kodicek.

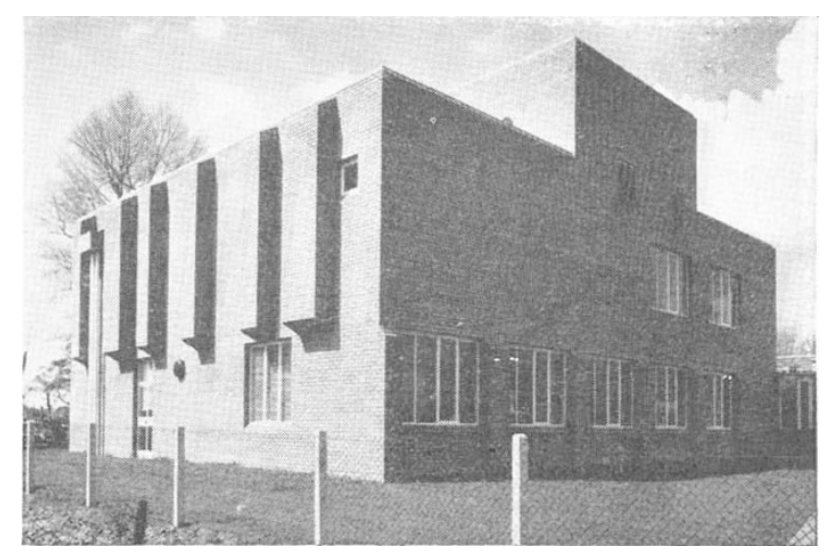

New extension to the Dunn Nutritional Laboratory.

The Dunn Nutritional Iaboratory was first established in Shaftesbury Road, Cambridge, in 1929 through the joint efforts of Sir Frederick Gowland Hopkins and Sir Walter Morley Fletcher-the then secretary of the Medical Research Council-to found a laboratory to be concerned with the physiology of human nutrition. The new extension, which was completed in February

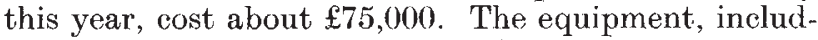
ing such items as an ultrasonic disintegrator, a Joyce Loebl Chromoscan densitometer, a spectrophotofluorometer and so on, is estimated to have cost another 